This paper is a reviewed and unpublished chapter of my doctorate theses named Bouè Soeurs ID7091: the cultural biography of a dress. It presents a commented biography survey of specialized literature in dress history, which may have influenced the actual national publications (both original and translated) and also have noticeably affected learning-teaching processes in Fashion Design programs.

Keywords: dress history, specialized literature, teaching-learning processes. 


\section{Notas sobre roupa na literatura especializada}

Rita

ANDRADE

Este artigo é um capítulo inédito e revisado de minha tese de doutorado intitulada Bouè Soeurs RG7091: a biografia cultural de um vestido, defendida no Departamento de História da PUC/SP, em junho de 2008. Trata-se de um levantamento bibliográfico comentado da literatura especializada em história do vestir (da moda e da roupa) que influenciou a conformação atual das publicações nacionais (originais ou traduzidas) e que afeta sensivelmente as relações de ensino-aprendizagem nos cursos de Design de Moda no Brasil.

Palavras-chave: história do vestir/da roupa, publicações especializadas, processos ensino/aprendizagem 
Ao longo do doutorado escrevi uma revisão bibliográfica que deveria ser o primeiro capítulo da tese (ANDRADE, 2008). Com o texto pronto, entretanto, a revisão não se acomodou bem no lugar previsto. Depois das questões levantadas pela banca de qualificação (a que sou muito grata, pelas observações que colaboraram para esta nova edição), o melhor arranjo seria o que privilegiava a apresentação do vestido Bouè Soeurs, e assim aconteceu.

Julguei, no entanto, que os dados coletados pudessem servir como um registro daquilo que já foi publicado e discutido sobre o assunto. Essa revisão está longe de dar conta de todas as publicações relacionadas à história da roupa, mas estão aqui alguns textos de referência na bibliografia internacional. Além deles, há ainda referência à publicações nacionais sobre moda, tema que prevalece sobre as roupas em nossa bibliografia.

\section{Os historiadores de moda no século $X^{1}$}

Entre 1900 e 1930, alguns trabalhos sobre a história do vestir foram publicados, mas não houve nenhuma mudança significativa em termos de abordagem teórica com relação às publicações anteriores, prevalecendo os panoramas gerais das histórias dos costumes. Apesar disso, há duas publicações excepcionais do período sinalizando abordagens que só viriam a se desenvolver décadas mais tarde. O primeiro deles é o estudo de Elizabeth McClellan, Historic dress of America (1906). Esse trabalho é notável, porque, além de ter sido escrito por uma mulher, o estudo era baseado na análise de objetos, das próprias roupas, que eram, segundo McClellan, veritable documents of history on the subject of dress in Amrica (TAYLOR, 2004, p.46). Apenas dali a oitenta anos esse tipo de abordagem seria utilizado em estudos na perspectiva da cultura material para a interpretação de roupas.

O segundo é o livro do pintor Talbot Hughes, An account of costume for artists and dressmakers, illustrated by the author from old examples (1913). Este também foi um trabalho baseado na observação de objetos, porém seu maior interesse esteve no estudo de roupas antigas (ou históricas) com a fina- 
lidade de desenvolver figurinos para teatro. Para isto, Hughes utilizou desenhos e modelagens que criou a partir da análise de roupas do século XVIII, parte delas do acervo do museu Victoria \& Albert de Londres. ${ }^{2}$

A história do vestir escrita entre as décadas de 1930 e 1960 traz duas grandes influências pautadas pelo gênero: de um lado, os historiadores (homens) e, de outro, as historiadoras. ${ }^{3}$ Enquanto os historiadores foram mais influenciados pela abordagem metodológica de Flügel (1930), segundo a qual o uso de roupas tem bases psicológicas (sexuais), as historiadoras seguiram os passos de Elizabeth McClellan, construindo análises sobre moda e roupa com base na interpretação de objetos.

James Laver e Cecil Willett Cunnington foram os "pais da história do vestir" no século XX e, apesar de suas origens britânicas, seus trabalhos (dúzias de livros publicados em inglês entre as décadas de 1930 e 1960 e traduzidos para várias línguas) influenciaram sobremaneira as abordagens de estudo, o que foi escrito e ensinado depois deles. Em 1937, Cunnington e Laver trabalharam juntos em um seriado da rede de televisão britânica BBC - "(The) first fashion and fashion history series Clothesline, a six-part, bimontly series" (TAYLOR, 2004, p.54). Entre outras coisas, o programa apresentava manequins vivos vestindo roupas de época fornecidas por Cunnington de sua vasta coleção de trajes históricos. Laver era o apresentador e havia ainda um cartunista que ilustrava cenas do cotidiano de mulheres e suas roupas.

Para nossa discussão, é curioso perceber pela descrição que Taylor faz das origens e formação dos dois historiadores (e rivais) que, apesar da proximidade que ambos tiveram com roupas históricas, chegando a estudá-las com o objetivo de datar certos estilos de moda, nenhum deles se aprofundou nessas análises, deixando que o pressuposto das razões psicológicas relacionadas ao vestir feminino suplantasse qualquer evidência que pudesse surgir da observação das roupas. Cunnington (1878-1961) e sua mulher, Phillis, eram médicos e historiadores do vestir e juntos possuíam uma coleção para pesquisa de roupas históricas. Cunnington escreveu: English women's clothing of the nineteenth century (1937), Why women wear clothes (1941) e The art of English dress (1948). 
Já Laver tinha interesse pelo teatro e chegou a escrever algumas peças de sucesso. Também escreveu sobre arte, impressos e história social, do teatro, da roupa e moda. TrabaIhou como curador de pinturas e desenhos no Museu Victoria \& Albert em Londres, de 1938 a 1959 (TAYLOR, 2004, p.51). É possível que o interesse específico pela história do vestir na Inglaterra tenha contribuído para que a popularidade de Cunnington fosse consideravelmente menor do que a de Laver em termos de público internacional. No Brasil, por exemplo, há traduções, edições e reedições dos trabalhos de Laver, mas não de Cunnington, que só é encontrado em poucas bibliotecas especializadas em edições da língua inglesa. ${ }^{4}$ Fato é que a visão de Laver e, em especial, a que é expressa em seu livro $A$ roupa e a moda (do original Concise history of costume de 1936), é a que predomina na historiografia especializada do século $X X$. Além de uma abordagem mais panorâmica de Laver sobre a história do vestir, foi sua personalidade carismática, que atendia tanto a grandes audiências quanto ao público de especialistas, a grande responsável pelo sucesso e difusão de seu trabalho na Inglaterra e no estrangeiro.

No centro das idéias defendidas por Laver (como por Cunnington) estava a de que o consumo feminino por roupas de moda tinha um fundo funcional: as mulheres se vestiam para atrair os homens, mas, como Taylor (2004, p.58) bem escreveu:

[...] este ponto de vista foi rigorosamente contestado entre as décadas de 1980 e 1990 por um grupo de historiadoras e pesquisadoras, incluindo Elizabeth Wilson and Amanda Vickery. Ambas, através de seus distintos estudos de caso, demonstram que o consumo de moda pelas mulheres teve e tem funções mais profundas do que tentar atrair o sexo oposto ou ascender socialmente, e que visões como as de Laver e Cunnington trivializaram o comportamento, os papéis familiares e sócio-culturais das mulheres. ${ }^{5}$

Das historiadoras, Taylor (2004) destacou o trabalho de duas curadoras britânicas: Doris Langley (cuja coleção pessoal de roupas formou a coleção de base do Museum of Costume, Bath) e Anne Buck (a primeira conservadora da Gallery of En- 
glish Costume, Platt Hall, Manchester, 1947-1972). ${ }^{6}$ Graças à proximidade que tinham com a documentação e análise de roupas, ambas construíram suas visões sobre a história do vestir com base na análise de objetos. Os trabalhos de Langley The women in fashion (1949) e The child in fashion (1953) - debatem a veracidade de alguns mitos populares na história da moda (como as cinturas extremamente finas das mulheres vitorianas), e têm uma abordagem sociocultural sobre os códigos do vestir, evitando a generalização de classe que prevalecia na historiografia. Buck, por sua vez, somou à perspectiva cultural os métodos de conservação e exposição museológicas voltadas para artefatos de tecido, metodologia que influenciaria novos métodos e abordagens de estudo a partir da década de 1950. Segundo Taylor (2004, p. 61-62):

Suas meticulosas pesquisas publicadas mesclam uma análise cuidadosa de vestimentas com o estudo de documentos de arquivo e são um raro exemplo de "boa prática". Estas são admiradas tanto por historiadores sociais quanto econômicos, um acontecimento igualmente raro, e que teve um impacto positivo no avanço de todo o campo da história do vestir/da vestimenta em nível internacional.

Anne Buck e Langley Moore são indubitavelmente nomes expressivos da historiografia do vestir, especialmente no que concerne às suas contribuições metodológicas, na análise de roupas e das funções socioculturais do vestir e do consumo femininos. Trabalhos recentes que utilizam a interpretação de objetos para estudos específicos se concentram na história da alta-costura. Dois dos melhores exemplos são uma biografia de couturier, Cristbal Balenciaga, de Lesley Miller (2007), e outro sobre o consumo de couture na América do Norte na década de 1950, Couture \& commerc, de Alexandra Palmer (2001).

Diferentemente do trabalho de Laver, a bibliografia sobre o uso de roupas como documento e sobre métodos de interpretação desses objetos não é traduzida para o português e é pouco conhecida no Brasil. 


\section{Aspectos da historiografia de moda (mais que da roupa) no Brasil: como nos posicionamos em relação à bibliografia internacional especializada}

A história do vestir no Brasil está ainda por ser escrita. Ao contrário dos colegas historiadores na Inglaterra, Chile, Estados Unidos, França e Itália, não temos um panorama da história da moda e da roupa brasileira, nem mesmo uma que inicie com a colonização portuguesa, período em que efetivamente as roupas e tecidos seriam encontrados aqui. Nossa contribuição para a bibliografia internacional sobre história da roupa - de moda ou não, do vestir, do costume, da indumentária - tem sido fragmentada. Na bibliografia internacional, o assunto "moda contemporânea brasileira" vem ganhando espaço editorial, situação muito diversa da ausência de tecidos e roupas históricos brasileiros nessas publicações. Jennifer Harris, curadora do museu The Whitworth Art Gallery em Manchester, ${ }^{7}$ Inglaterra, conhece tecidos e trajes típicos de países da América Latina como Peru, Venezuela, México, Guatemala e Chile (dos quais o museu possui exemplares), mas ressente-se de não conhecer tecidos e trajes típicos brasileiros: o museu não possui um fragmento sequer identificado como originário do Brasil. ${ }^{8}$

Até o surgimento dos cursos de graduação em Moda no Brasil (final da década de 1980), os estudos, pesquisas e publicações relacionadas ao assunto parecem ter resultado de esforços e interesses individuais, e ficaram vinculados a determinadas instituições: de ensino (cursos de diversas áreas, especialmente as de Humanas, em universidades - sobretudo as privadas), de pesquisa (museus e também universidades) e de interesses privados (individuais e empresariais, como as publicações comemorativas comissionadas por empresas). De qualquer maneira, não sabemos qual foi o primeiro trabalho ou a primeira publicação brasileira a tratar da moda e roupa no país. Não apenas isto, mas, apesar de algumas tentativas isoladas e recentes em abordar a historiografia do vestir no Brasil, ainda sabemos pouco sobre as "mentalidades" (ao modo de Taylor) que sustentaram nossos recortes no estudo e escrita das nossas formas de vestir. As recentes publicações nacionais e as traduções de antigas publicações estrangeiras é que têm ser- 
vido para ocupar esse espaço em nosso imaginário e têm sido amplamente aceitas como o início das publicações sobre roupa e moda no país.

São, portanto, as publicações recentes elaboradas por autores brasileiros e as publicações antigas, estrangeiras, traduzidas para o português, que formam o conjunto da bibliografia específica disponível no Brasil. Essa bibliografia representa nossos interesses temáticos de pesquisa e representa também a base sobre a qual estamos construindo nossa visão de mundo e nossas abordagens metodológicas. Vejamos, isto posto, de que natureza são essas publicações e o que nelas conhecemos sobre a história do vestir brasileiro.

\section{Métodos e abordagens}

Adilson José de Almeida (1995, p.251), historiador responsável pelo departamento de objetos do Museu Paulista da USP, listou e comentou uma bibliografia selecionada de livros sobre indumentária e moda publicados em língua portuguesa (originais ou traduzidos) no período de 1979 a 1996, critério de seleção que o autor explica:

[...] permite dispormos de um referencial básico para uso imediato tanto científico, como informativo ou de divulgação [...]; possibilita também uma caracterização inicial do campo editorial entre nós, observando-se os interesses, temas e enfoques dominantes $[\ldots]$.

Dessa listagem, Almeida concluiu que o maior interesse de pesquisa recai sobre as roupas de moda (e menos sobre as roupas de trabalho ou sobre uniformes), o que pode ter levado à supremacia de textos que tratem da "circulação e o consumo" em detrimento dos problemas de produção (ALMEIDA, 1995, p.251). A história do vestuário é o gênero mais encontrado, e é seguido pelas biografias (de estilistas e marcas) e pelas obras de referência como glossários e guias, esses em muito menor número do que o primeiro. Já em outras áreas como sociologia, antropologia e semiologia da moda, as publicações eram 
mais escassas até o período delimitado por Almeida, 1996, e sobre elas escreveremos mais adiante. Como bem observado pelo autor, "a grande maioria destas publicações são obras de divulgação, não voltadas para a produção de conhecimento novo" (ALMEIDA, 1995, p.252).

Dos quase cinqüenta trabalhos listados, Almeida identificou quatro padrões da análise que ainda hoje podem ser identificados como predominantes nas publicações sobre moda e indumentária disponíveis em português. Os quatro padrões são representados por uma publicação cada e, dentre eles, apenas uma é de autora brasileira, sendo que as demais são traduções amplamente conhecidas (com exceção do trabalho de Sahlins, 1979) e adotadas nos cursos de moda no Brasil.

A primeira é o Sistema da moda (do original em francês Le sisteme de la mode de 1967), de Roland Barthes, cuja primeira edição brasileira data de 1979. O segundo padrão metodológico estaria na obra de Marshall Sahlins, Notas sobre o sistema do vesturio americano (1979). Nesse trabalho, à semeIhança de Barthes, Sahlins procurou desenvolver um método de análise estrutural para um estudo sistemático do vestuário ${ }^{9}$ (norte-americano) como sistema de comunicação. Trata-se de abordagens que diferem daquelas mencionadas por Taylor (em análises baseadas em objetos) no que diz respeito à intenção que antecede a pesquisa. Em outras palavras, enquanto Buck e Langley consideraram as evidências particulares de cada roupa estudada, Sahlins, por exemplo, procurou estabelecer "categorias culturais" nas quais os objetos estudados pudessem ser enquadrados - assim, teríamos, por exemplo, roupas de lazer ou trabalho; roupas de verão ou inverno; roupas de elite e de trabalhadores. A influência de uma abordagem lingüística é evidente nesses trabalhos (ALMEIDA, 1995, p. 259).

O terceiro padrão foi encontrado em Gilles Lipovetsky, na obra Imprio do efmero: a moda e seu destino nas sociedades modernas (1989), indubitavelmente o trabalho de maior influência nos estudos de moda no Brasil. Nesse trabalho, Lipovetsky defende a idéia de que a moda, de origem aristocrática européia, é um fenômeno ocidental moderno (democrático) que ao longo de sua história (a partir do século XIV) deixou 
de ser periférico para ser hegemônico. Lançado na França em 1987, a visão do autor, sociólogo de formação e professor atuante, causou polêmica entre seus colegas e ainda hoje as idéias ali expressas não são unanimemente aceitas. De qualquer maneira, a grande contribuição de Imprio do efmero está no seu estudo histórico da moda em que é possível "apreender as linhas gerais de seu desenvolvimento e as razões para as mudanças verificadas" (ALMEIDA, 1995, p. 265). A obra de Lipovetsky marca um momento de transição nos estudos e na historiografia do vestir e, ainda que haja contradição em sua abordagem metodológica, é inegável que sua obra tenha colocado o assunto moda em evidência em esferas acadêmicas internacionalmente.

O quarto padrão identificado por Almeida está em $O$ esprito das roupas: a moda no sculo XIX (1987), de Gilda de Mello e Souza. Este é um trabalho importante para a bibliografia especializada no Brasil. Primeiro porque foi escrito por uma mulher e defendido como tese em 1951 na ECA/USP- uma audácia para a época. Depois, porque o tema não era assunto "legítimo" para ser estudado nas universidades. Há três questões que norteiam as análises da autora: as diferenciações de gênero, muito marcantes no século XIX; a moda como expressão artística; e a competição entre estratos sociais exercida pela imitação. As duas primeiras questões estariam subordinadas à terceira.

As influências teóricas no trabalho da autora são claramente identificadas - Veblen, Simmel, Flugel, Laver e, uma novidade na historiografia, Walter Benjamim (reprodutibilidade técnica versus expressão artística). Suas principais fontes primárias são pinturas e fotografias do século XIX, cujas reproduções no livro são sempre acompanhadas de uma legenda em que a autora busca analisar através das características estéticas das roupas (algumas vezes também dos gestos e posturas corporais) os aspectos marcantes da moda do século e as transformações nele ocorridas. Apesar de sua tentativa em fazer uso de alguns aspectos materiais das vestimentas (como cores e formas), faltava-Ihe um suporte metodológico que estaria ausente nos autores por ela explorados. 
O último padrão está no trabalho de Alice Rangel de Paiva Abreu, Avesso da moda: trabalho a domiclio na indstria de confeco (1986). Este é "um estudo em sociologia do trabalho no qual analisa-se[sic] a estrutura do emprego feminino e as condições de trabalho num setor específico da indústria de confecção brasileira: as oficinas de confecção de roupa feminina de alta qualidade (vendidas apenas em butiques), na cidade do Rio de Janeiro" (ALMEIDA, 1995, p. 277). Utilizando-se de E. Thompson, a autora explora os interesses econômicos no uso de trabalho a domicílio considerando valores culturais atrelados a ele, especialmente os relacionados à divisão e diferenciação de gênero no universo de trabalho (de confecção).

Neste estudo percebemos uma mudança de abordagem de estudos relacionados à moda e a roupa no Brasil, especialmente vista no embasamento teórico (Thompson), o que permitiu à autora analisar valores culturais dentro do contexto específico da costura de roupas de alta qualidade. Abreu nos apresenta uma diversidade cultural fora do modelo de difusão vertical da moda por imitação (tricle-down). Seu maior interesse esteve, no entanto, nas relações de trabalho, e o estudo do vestuário (da roupa) foi secundário. Com todas as contribuições que esse estudo trouxe ao conhecimento da produção de roupas no Brasil, ele ainda ocupa em espaço marginal nas bibliotecas especializadas, raramente aparece nas bibliografias dos cursos de moda e é muito menos popular do que Laver e Kohler entre estudantes e professores.

A partir de 1995, o mercado editorial de moda no Brasil cresceu consideravelmente sem que, contudo, houvesse uma mudança representativa nas abordagens de estudo do vestir. Novos debates parecem acontecer em outras áreas das quais os profissionais de moda (entre eles professores, alunos, pesquisadores) têm buscado participar. Com a criação de cursos de pós-graduação em moda e indumentária no final da década de 1990, núcleos de estudo e pesquisa especializados começaram a ser formados nas escolas de moda. Os debates internos aos cursos têm fomentado a divulgação de estudos mais recentes, e o reflexo dessas iniciativas já começa a ser sentido no ensino e nas práticas de pesquisa da história do vestir no Brasil. 
Exemplo dessas iniciativas é o Núcleo Interdisciplinar de Estudos da Moda (NIDEM) da Universidade Paulista, criado em 1998 pela reunião de "um grupo de pesquisadores de diversas áreas das Ciências Humanas" na sede do curso de moda da universidade (WAJNMAN; ALMEIDA, 2002). O primeiro projeto do núcleo, intitulado Moda Contempornea e Construo Interdisciplinar: Pela Constituição de um Campo Científico Para a Moda (apoiado pela FAPESP), resultou na publicação dos textos de debates e pesquisas individuais de seus pesquisadores, reunidos no livro Moda, comunicao e cultura: um olhar acadmico (WAJNMAN; ALMEIDA, 2002).

A criação do Colóquio de Moda, ${ }^{10}$ em 2004, evento anual que reúne professores, pesquisadores e alunos das escolas de moda brasileiras, é outra iniciativa de um grupo de pesquisadores das áreas de Ciências Humanas, que tem colaborado para ampliar os debates sobre as práticas de pesquisa e ensino no Brasil. É fato, no entanto, que a falta de recursos destinados à organização dos encontros anuais (que não conta com apoio de instituições financiadoras de pesquisa), colabora para a marginalização (ainda) desta área de estudo e pesquisa no país.

As publicações lançadas nos últimos dez anos revelam alguns dos desdobramentos alcançados por meio das iniciativas dos cursos de moda, como os citados acima. Elas apontam alguns interesses recentes dos pesquisadores e acentuam, por outro lado, a permanência de abordagens e temas há muito presentes na bibliografia especializada. Elas são dos seguintes tipos:

\section{Periódicos científicos}

Em 2002 dois periódicos mudaram o cenário das publicações específicas de moda no Brasil: Fashion Theory A Revista da Moda, Corpo e Cultura, traduzida para o português da original inglesa Fashion Theory The Journal of Dress, Body and Culture (publicado desde 1996), pela editora Anhembi Morumbi, e Moda e Palavra Reflexes em Moda, publicação do departamento de Moda da Universidade Estadual de Santa Catarina (UDESC). 
Ao conteúdo do original inglês da revista Fashion Theory era acrescido um ou dois artigos de autores brasileiros. A versão nacional da revista trouxe duas grandes contribuições aos debates acadêmicos: permitiu que as pesquisas dos autores brasileiros pudessem circular entre colegas de várias instituições, de vários Estados, indicando caminhos externos ao predominante eixo Rio de Janeiro-São Paulo; permitiu ainda que novas abordagens e métodos de pesquisa internacionais (não apenas da Europa, mas da China, Índia, Austrália e África) fossem introduzidos aos leitores brasileiros com maior agilidade e sem menos qualidade do que publicações mais caras (em geral, livros) e ainda não traduzidas.

O formato de revista e a sua periodicidade (trimestral) possibilitaram o uso freqüente de artigos por professores nas escolas de moda. A edição brasileira gerou encontros e fomentou a pesquisa acadêmica amplamente, como pudemos ver nos desdobramentos dos conteúdos da revista. Exemplos disso são: mesa de discussão sobre Fotografia de Moda no Brasil mediada pelo articulista Orlando Maneschi (Especial Moda e Fotografia, v. 1, n. 3, set. 2002); palestras com articulistas brasileiros nas universidades brasileiras e em encontros como o Sexta da Moda, da Universidade Anhembi Morumbi; criação de curso de extensão pela jornalista Astrid Façanha (Senac Moda - São Paulo) baseado na abordagem de Ginger Gregg Duggan (Fashion Theory, ed. bras., v.1, n.2, junho 2002, p.330), em seu artigo sobre performance e desfiles de moda contemporâneos.

Além das iniciativas geradas a partir dos conteúdos da revista em São Paulo, os debates e a sua repercussão em vários outros Estados, como Santa Catarina, Bahia, Goiás e Minas Gerais, significaram uma considerável mudança de concentração dos debates no sudeste do país. A edição brasileira da revista deixou de ser publicada em 2005, seguindo o padrão de descontinuidade de publicações dessa área.

A revista Moda e Palavra, publicada pela UDESC, é a reunião de artigos escritos por professores do departamento de Moda da universidade e de outros autores convidados, "profissionais reconhecidos academicamente". Tem por objetivo 
"promover o debate, contribuindo para o pensar brasileiro suscitado nos diversos centros de ensino espelhados pelo Brasil". A professora Mara Rúbia Sant Anna (2002, n.p.), na apresentação do primeiro número da revista, ainda se ressentia da falta de análise crítica sobre a moda nas publicações nacionais:

O consenso encontrado nas páginas que se seguem está na concepção da carência de um trabalho de relevância acadêmica que aborde a Moda, seja enquanto teoria social e histórica seja enquanto produto material e tecnológico da sociedade capitalista. Nesta última dimensão a pobreza de reflexão é menor, na medida em que as pesquisas na área da Engenharia Têxtil, da Administração e do Design, entre outras, têm permitido avanços consideráveis na qualificação do produto de moda oferecido em nossa sociedade. Contudo, mesmo neste âmbito, a especificidade da Moda, geralmente, é pouco acentuada, quando não, equivocadamente abordada.

Para Sant Anna (2002), as abordagens empregadas pelos articulistas deveriam considerar que moda "não é roupa nem linguagem trans-histórica", e sim "[ela é] o próprio sistema que permite a existência desta linguagem e nos faz ler e sermos lidos por aquilo que carregamos na aparência" e mais, "moda é entendida como a própria dinâmica da construção da sociabilidade capitalista e como tal, a aparência deve ser entendida como a "essência" desse universo". Prevalece, portanto, a visão de que moda é mais o sistema, a engrenagem que azeita o capitalismo moderno ocidental do que o objeto material resultante dele. Em especial a dualidade tecnologia (fazer) x teoria (pensar e, em geral, pela Comunicação), vistos em contraposição, sugere que ainda há entre nós uma resistência em lidar com a materialidade como componente também do pensar e não apenas do fazer.

Um lançamento recente abriu espaço para novas discussões e abordagens. A revista dObras uma revista de moda mas no $s$, acadmica mas nem tanto (São Paulo: Estação das Letras e Cores) foi lançada em outubro de 2007 e está em seu sétimo número (set. 2009). Abrigando colunas temáticas, artigos e entrevistas, as editoras (Kathia Castilho e Anthoula Fiskatorys) criaram um meio para debater questões muito presentes entre profissionais 
da cadeia produtiva têxtil e, especialmente, entre pesquisadores dos cursos de graduação e pós-graduação em Moda no país e América Latina.

\section{Traduções de publicações recentes (últimos vinte anos)}

Das traduções feitas a partir de publicações estrangeiras dos últimos vinte anos, destacamos três que foram rapidamente incorporadas às bibliografias adotadas nos cursos de moda no Brasil. Moda como Comunicao, de Malcolm Barnard, originalmente publicado em inglês (1996), ${ }^{11}$ é o mais popular deles e introduz a moda e a roupa como agentes que comunicam classe e identidade sociais, gênero e sexualidade. Por uma abordagem teórica cultural (especialmente derivada de Baudrillard), Barnard entende a moda como um fenômeno moderno e pós-moderno. Sua análise baseia-se, sobretudo, em fontes literárias e iconográficas. Este trabalho tem sido consideravelmente empregado em disciplinas que analisam a moda contemporânea ou que discutem teoria de moda.

Fetiche: moda, sexo e poder, de Valerie Steele, ${ }^{12}$ aborda a moda pelo ponto de vista da história da cultura, analisando o uso de um vestuário pensado e produzido especialmente para fetichizar o corpo, transformando-o em objeto de desejo e atribuindo-lhe valores que variam historicamente. Estudando alguns ícones do vestuário fetichista como o espartilho, a bota de couro e o salto alto, Steele (1997, p.174) discute aspectos psicológicos que permeiam o design desses objetos-mercadorias visto, por exemplo, na idéia de que "um fetiche é uma história mascarada em um objeto". Suas principais fontes são catálogos e periódicos e sua análise deriva do estudo das imagens e textos ali presentes.

Moda e Guerra: um retrato da Frana ocupada (2004), ${ }^{13}$ da historiadora francesa Dominique Veillon, trata da história da alta costura francesa no período de ocupação alemã em $\mathrm{Pa}$ ris durante a Segunda Guerra Mundial. Fornece um panorama bastante realista da produção e comercialização das roupas desse tipo de confecção, acentuando as mudanças de design e de matérias-primas decorrentes das ações da guerra. Abor- 
da ainda o uso político da moda que, pelo lado alemão, procurava enfraquecer o poder francês (quando tenta transferir a indústria da alta costura francesa para Berlim) e, pelo lado francês, buscava nela formas de consolidar o poder nacionalista (quando defende a permanência da alta costura em seu país de origem). Este trabalho passou a integrar a bibliografia de disciplinas ligadas à história da moda nos currículos dos cursos no Brasil.

Das últimas publicações traduzidas para o português, uma das mais recentes é, para nosso interesse de estudo, a mais significativa delas. Trata-se de Cultura das aparncias: uma histria da indumentria (sculos XVII-XVIII), do historiador francês Daniel Roche, traduzida e publicada em 2007 no Brasil pela Editora SENAC de São Paulo. ${ }^{14}$ O estudo de Roche (2007, p.2021) originalmente publicado em francês em 1989 demonstra que é a roupa "o termo que melhor convém a uma história social e cultural das aparências" e, fazendo uma crítica às antigas abordagens ao estudo do vestir, demonstra ainda que

[...] uma nova problemática da história da roupa é uma maneira de ir direto ao coração da história social; é uma maneira nova de colocar a questão essencial - o que deve ser produzido? - e seu cortejo de interrogações subseqüentes: o que deve ser consumido? O que deve ser distribuído? É também uma maneira útil de tentar observar como os diferentes modelos ideológicos, que coexistem e disputam a regulamentação das condutas e dos hábitos, interagem na realidade que pretendemos apreender.

Roche (2007, p.23) acredita que a roupa revela os códigos das civilizações e que na sua história, a história da roupa, estão imbricados (e não contrapostos) o real e o imaginário, situação que gera maior dificuldade de pesquisa, já que será preciso buscar auxílio em fontes menos convencionais como roupas e tecidos (além daquelas mais familiares como as "fontes pictóricas", as "fontes da história social, familiar ou comercial, e as fontes filológicas"). Em seu primeiro capítulo, "Vestimentas ou costumes", o autor faz um breve, porém esclarecedor, apanhado de cada tipo de fonte relevante ao estudo da roupa para uma história da roupa. Ainda que Roche trate do contex- 
to francês e dos séculos XVII e XVIII, este trabalho, e sua tradução para o português, poderá ser a maior contribuição para discussões acerca do uso de fontes no estudo e escrita de uma história da roupa no Brasil.

Das últimas traduções publicadas até a edição deste texto, é preciso citar Histrias da Moda, do atual presidente da Federação Francesa da Costura, Didier Grumbach. Lançado no início de 2009 pela editora Cosac Naify (uma das editoras que tem se especializado na tradução e publicação de títulos de moda), o livro traduzido do original francês (1993) trata de apresentar e historicizar os meandros da alta costura parisiense do século XIX à atualidade. A publicação teve patrocínio do Instituto Nacional de Moda e Design com apoio do São Paulo Fashion Week (maior evento nacional do setor), sinalizando que o luxo é um tema importante tanto no cenário industrial-comercial quanto no editorial-educacional.

\section{Coleções de núcleos editoriais}

O aumento das publicações da área encontra nos cursos de moda o maior incentivador. A Editora da Universidade Anhembi Morumbi tem sido, ao lado da Editora do SENAC (cujo Centro Universitário também oferece cursos de moda em nível superior - graduação e pós-graduação), ${ }^{15}$ das que mais publica títulos sobre moda.

É da Editora Anhembi Morumbi a primeira coleção de livros cujos temas vêm dos currículos dos vários cursos que a escola oferece. A coleção Moda e Comunicação coordenada por Kathia Castilho "reúne os conteúdos produzidos para as disciplinas do curso de Pós-Graduação em Moda e Comunicação on-line da Universidade Anhembi Morumbi"; para Castilho (BRAGA, 2004, p.11):

o crescente número de instituições de ensino, assim como o número de alunos de graduação e pós-graduação em moda em todo o Brasil, evidenciam a necessidade de publicarmos nossos estudos e pesquisa gerando assim uma bibliografia qualificada e imprescindível para o estudo nesta área. 
Fazem parte da coleção oito livros publicados entre 2004 e 2006, todos amplamente referenciados na bibliografia dos cursos de graduação e pós-graduação em moda por todo o país. ${ }^{16}$

Além dessa coleção, a Editora Anhembi Morumbi publicou outros trabalhos derivados de seus cursos de Moda. O primeiro deles, hoje esgotado, foi O universo da moda, do sociólogo Dario Caldas, inicialmente elaborado como curso à distância em 1997. A introdução ao livro é um relato pessoal bastante revelador dos desafios enfrentados por professores e pesquisadores naqueles anos iniciais dos cursos on-line. Ao descrever sua trajetória profissional e sua formação no exterior, Caldas (1999, p.15) escreveu:

[...] comecei a refletir sobre o método apropriado a um enfoque cultural e comportamental sobre moda. Ele teria, necessariamente, de se referenciar na história da cultura e das artes. As Ciências Sociais deveriam trazer o entendimento da dinâmica dos grupos sociais, dos processos de mudança e de evolução dos valores. A semiologia, com base na teoria da comunicação, permitiria ler a moda como texto não-verbal, no sentido de que a roupa é uma "máquina de comunicar" (MAFFESOLI, 1996) como o é uma embalagem ou um spot publicitário. Além disso, o conjunto de teorias que explicam o funcionamento do mercado seria uma ferramenta útil, visto que a moda e o consumo são indissociáveis.

A preocupação do autor em tratar dos vários aspectos da moda numa única publicação representa bem aquele momento. Os cursos de graduação existiam então há uma década e passavam do estágio inicial de formação das matrizes curriculares para assimilar algumas novas teorias e abordagens vindas, sobretudo, de escolas estrangeiras, especialmente as francesas e italianas. Faria sentido, portanto, que a preocupação expressa pelo autor encontrasse nas disciplinas de conteúdo abrangente, como Universo da Moda ou Introdução a Moda, uma base exploratória das muitas possibilidades vindouras que mereceriam especialização em outros momentos no processo de formação acadêmica. Tratava-se, para Caldas (1999, p.19), de criar "uma espécie de postulado inicial' para 'alargar as fronteiras do mundo da moda". 
Pouca mudança foi vista no mercado editorial brasileiro no final da década de 1990, que foram seguidos por um assombroso crescimento no número de publicações, não implicando, necessariamente, uma mudança representativa de variedade de temas e abordagens. Em 2002, além dos periódicos tratados anteriormente, outros dois lançamentos reforçaram a predileção nacional pelas abordagens ligadas à comunicação e, particularmente, à semiótica. O número especial da revista Nexos, Comunicação, Educação e Moda (CASTILHO; ANDRADE,2003), publicada pela Editora Anhembi Morumbi, apresentava sete artigos de professores de seus cursos de moda, cinco dos quais tratando de aspectos da relação entre moda e comunicação; ${ }^{17}$ e o livro O sensacional da moda, da comunicóloga Ana Mery Sehbe De Carli (2002). Esta última foi publicada pela editora da Universidade de Caxias do Sul e, ao lado da revista Moda e Palavra, da Universidade Estadual de Londrina, sinalizam que houve um aumento no número de pesquisas e publicações fora de São Paulo e Rio de janeiro.

De fato, outros trabalhos de professores de cursos de Moda do sul e nordeste brasileiros sugerem que, neste início de século, estejamos vivendo uma descentralização dos estudos relacionados à moda. São exemplos os trabalhos da professora Miriam da Costa Manso Moreira de Mendonça, O reflexo no espelho: o vesturio e a moda como linguagem artstica e simblica (Editora UFG, 2006), coordenadora do curso de Design de Moda da Universidade Federal de Goiás; e Sentidos da moda (vesturio, comunicao e cultura) (Annablume, 2005), da professora Renata Pitombo Cidreira, coordenadora do curso de graduação em Comunicação e Produção de Moda da FTC em Salvador, Bahia.

Algumas publicações nasceram (e foram ampliadas a partir) de encontros e congressos temáticos que apontaram para novas discussões e debates sobre a moda. Foram duas as publicações desse tipo lançadas entre 2002 e 2006: A moda do corpo, o corpo da moda (2002) nasceu do seminário homônimo realizado na PUC/RJ e organizado pelos cursos de Design em parceria com a Universidade Anhembi Morumbi/SP e com o grupo de pesquisa ETHOS - Comunicação, Comportamento 
e Estratégias Corporais, da Escola de Comunicação - da UFRJ; e O novo luxo (CASTILHO; VILLAÇA, 2006), que nasceu do encontro homônimo realizado em 2005 pela mesma parceria entre a Universidade Anhembi Morumbi/SP e a UFRJ.

A descontinuidade de publicações de periódicos e a falta de reimpressões revisadas dificultam a circulação das pesquisas e, conseqüentemente, da formação de cursos de pós-graduação. Dos mais de 140 cursos de graduação inscritos no Ministério da Educação (entre os oferecidos por escolas públicas e privadas, ver anexo), muitos são intitulados Design de Moda quando seus currículos e estrutura física apresentam, por vezes, maior concentração em Comunicação ou Administração. A especialização tem acontecido paulatinamente e por esforços ainda mais pessoais que institucionais, cenário este que apresenta alguma recentíssima mudança, como vimos pelas publicações nascidas dos encontros mencionados.

\section{Enciclopédias, dicionários, boletins e relatórios especializados}

Nos últimos anos percebemos um maior interesse na elaboração e tradução de algumas enciclopédias e dicionários de moda. É provável que a primeira tradução brasileira tenha sido a Enciclopdia da Moda (Companhia das Letras, 1992), de Georgina O'Hara, num período que coincide com o início dos cursos de moda em São Paulo. ${ }^{18}$ É mesmo possível que a abertura dos primeiros cursos de moda, ainda no embrionário estágio de cursos técnicos ou de extensão da década de 1980, tenha contribuído para novas publicações desse tipo, pois, em 1986, o núcleo editorial do SENAI/Cetiqt publica o Glossrio txtil e de confeco: ing/s-portugus (Rio de Janeiro). Esse foi seguido pelo Decifrando a moda: glossrio, de Airton Spengler (São Paulo: STS, 1993), e pelo Dicionrio da moda: guia de referncia de termos do mercado txtil e moda (2002), edição do Instituto Francisca Peixoto, com patrocínio da Companhia Industrial Cataguases.

Novas publicações são: uma reedição da enciclopédia de Georgina O'Hara (2007), com ilustrações em preto e branco (a ante- 
rior, de capa dura, tinha ilustrações coloridas impressas em papel coucher) e o acréscimo de verbetes brasileiros; a Moda ilustrada de A a Z (São Paulo: Manole, 2003) de Regina Maria Catellani; e o Dicionrio da Moda, de Mario Sabino (2006).

Entre os diretórios e guias que mapeiam as indústrias têxteis e de confecção em termos de localização e de especialidade de produção, destacamos o Guia TexBrasil, organizado pela Associação Brasileira da Indústria Têxtil e de Confecção, ABIT, e disponível no site www.abit.org.br, o Quem quem na cadeia txtil, da revista eletrônica Textília Press (www.textilia. com.br).

Relatórios setoriais são importantes instrumentos de análise mercadológica utilizados para planejamento estratégico por empresas do setor têxtil e de confecções. Por seu conteúdo informativo e por suas análises comparativas, poderiam ser adotados pelos cursos de moda, mas raramente aparecem entre as publicações indicadas nas bibliografias curriculares. São exemplos desse tipo de publicação o relatório anual setorial, editado pelo jornal Gazeta Mercantil de So Paulo e os Relatórios anuais do Setor Têxtil Brasileiro (cuja primeira edição data de 2003) e da Indústria Confeccionista Brasileira (cuja primeira edição data de 2001) editados pelo Instituto de Estudos e Marketing Industrial, IEMI.

Das publicações especializadas, o Boletim Industrial Txtil (BIT), editado pelo SENAI/CETIQT do Rio de Janeiro e publicado até 2000, é dos mais técnicos em conteúdo e aborda problemas bastante específicos das várias etapas de produção têxtil, das fibras, às etapas de fiação, beneficiamento e tecelagem. Editado em formato de bolso e de poucas páginas, o boletim era um informe dos títulos, seguidos de um breve resumo dos mais recentes artigos nacionais e internacionais disponíveis no núcleo de estudo e pesquisa setorial do SENAI. Cópia dos textos completos eram enviados sob encomenda.

\section{História da moda no Brasil: algumas considerações}

A pesquisa e publicação da história da moda no Brasil per- 
manecem ainda fragmentadas. A roupa é um assunto mais encontrado em romances, novelas e memórias do que em estudos especializados como acontece na bibliografia internacional. ${ }^{19}$ Encontraremos nas obras de autores como José de Alencar, João do Rio e Alcântara Machado menção às formas de vestir e, algumas vezes, a descrição de roupas específicas de determinadas épocas. Além deles, encontraremos nas pesquisas sobre a sociedade brasileira e sua formação alguma descrição sobre roupas, tecidos e fibras. É o caso, por exemplo, de Caminhos e fronteiras de Sérgio Buarque de Holanda (2005, 3. ed., 3. reimpr., 1a ed. 1956), em que o autor narra técnicas de fiandeiras do século XVIII e o uso de fibras locais hoje não mais conhecidas.

Os mais recentes lançamentos das produções nacionais refletem a predileção pela moda e suas relações com as cidades, caso dos livros Moda e sociabilidade: mulheres e consumo na So Paulo dos anos 1920, de Maria Claudia Bonadio (SENAC, 2007), e A cidade e a moda: novas pretenses, novas distines Rio de Janeiro, sculo XIX, de Maria do Carmo Teixeira Rainho (UnB, 2002). As cidades de São Paulo e Rio de Janeiro, bem como o período - século XIX e início do XX - são ainda recorrentes na historiografia especializada.

Outros temas de publicações recentes que resultaram de trabalhos de dissertações e teses, reforçam a predileção por determinados temas, especialmente moda, cidade e trabalho feminino. Mais, demonstram a predominância da roupa de moda em detrimento a outros tipos de roupas, como uniformes e roupas de trabalho. O historiador Adilson José de Almeida (2003) apurou que, até 2003, em importantes universidades brasileiras (PUC/SP, USP e UFRJ) já se realizou um total de 54 trabalhos entre dissertações de mestrado e teses de doutorado.

A maioria desses trabalhos fora realizada em departamentos de Comunicação, Ciências Humanas e Artes, áreas próximas às questões mais abordadas nos estudos sobre Moda. Há ainda os títulos que abordaram a moda enquanto meio gerador ou produtor de sentido na sociedade atual, discutindo bases teóricas das áreas de comunicação, filosofia, sociologia e psicologia na tentativa de entender a moda no contexto da modernidade. 
Exemplos são Teoria de moda: sociedade, imagem e consumo, de Mara Rúbia Sant Anna (Estação das Letras, 2007), e Os sentidos da moda (vesturio, comunicao e cultura), de Renata Pitombo Cidreira (Annablume, 2005). No que diz respeito especificamente à história da moda e do vestir no Brasil, repetimos, os estudos concentram-se em determinadas temáticas e ainda não é possível entrever um panorama desse aspecto de nosso patrimônio cultural.

É provável que as primeiras tentativas de escrever sobre a história da moda no Brasil tenham partido das editoras e articulistas de moda das revistas femininas desde o surgimento desse tipo de publicação no país, no século XIX (BARDUY, 2006). Ainda que de maneira fragmentada e sem o objetivo de compilação de uma "história total" da moda, os textos ali publicados sugerem uma espécie de reconhecimento da capacidade brasileira de estar na moda e de conhecer sua história para, então, lançar-se às novidades. Na Revista Feminina publicada em São Paulo (e vendida em todo o país) entre 1915-1936, encontramos textos que analisam a evolução da moda (européia) e a assimilação ou refugo de novas tendências no Brasil.

A primeira publicação nacional voltada exclusivamente à história da moda que pudemos localizar foi Trs sculos de modas, do escritor maranhense João Affonso do Nascimento, cuja primeira edição, de 1923, fora reimpressa em 1976 em homenagem do Conselho Estadual de Cultura ao 360 aniversário da fundação de Belém do Pará. O autor descreve a indumentária feminina e masculina percorrendo três séculos de história - 1616 a 1916 -, rememorando fatos relevantes de mudanças de estilo e de impactos da história social e econômica sobre a moda. A análise histórico-social do "fenômeno moda" parece ter sido influenciada pela abordagem de Veblen. O inovador nessa publicação, contudo, é a menção a aspectos regionais da moda e uma tentativa de historicizá-los. Nos capítulos finais, Nascimento descreve trajes típicos regionais das negras e mulatas do Maranhão e do Pará e procura entender de que forma deu-se a influência estrangeira para que abandonássemos aquelas formas de vestir. Os desenhos que acompanham o texto foram copiados pelo autor de "documentos que [possuía]" e ilustram 
o cotidiano do Brasil na fase de sua colonização. Em termos de estilo e abordagem, este trabalho em muito lembra aqueles citados por Lou Taylor em sua análise do uso das imagens na construção (para não dizer invenção) de uma história do outro.

As ilustrações do autor remetem aos desenhos dos viajantes que passaram pelo Brasil e registraram algumas formas de vestir dos "nativos", formas similarmente vistas em outras "civilizações distantes" como a África e Ásia. Os capítulos abordam a história da moda por blocos periódicos. No último desses blocos (1901-1916) temos exemplos emblemáticos das descrições detalhadas (e por vezes vistas por um viés moralista) dos trajes e da visão do autor acerca da influência estrangeira sobre a moda vestida no Brasil, como lemos nos trechos:

[...] as saias sobem, muito além dos limites traçados às de $1810 \mathrm{e}$ 1830; os decotes descem, mais do que poderia permitir a simples e honesta decência; suprimem-se as mangas, e até mesmo nos vestidos de baile, as sumárias alças que, à guisa de suspensórios, passando por cima dos ombros, sustentariam o corpete. E nada protege os braços, totalmente nus. As luvas, outrora complemento obrigado do vestido de uma senhora que se prezasse, as luvas, que, no caso em apreço, seriam bastante longas, - de pelica ou de malha de seda - indo acima dos cotovelos, são dispensadas: trazem-se séries de braceletes, colocados em várias alturas, à maneira das orientais, - de ouro, de prata, de madeiras diversas, de osso, de vidro, de celulóide, de tartaruga [...], ressurgem os brincos de nossas tetravôs, compridos, pesados [...]. Há também os vestidos [...], vestimenta muito parecida com uma camisola de bebê, ou um penteador, com que algumas mulheres não hesitam em sair à rua, trajando aquilo que antigamente só usavam na intimidade de alcova ou do toucador (NASCIMENTO, 1976, p. 181212).

Apesar da observação feita pelo neto de Nascimento, Francisco Paulo do Nascimento Mendes, na introdução da segunda edição do livro, de que o texto "parece convidativo para um estudo semiológico da moda", a familiaridade do autor com detaIhes de acabamento e de matérias-primas das roupas - braceletes de "celulóide" e "sumárias alças" ao modo de suspensórios - sugere que ele as estudou de perto, uma abordagem característica de estudos realizados em museus e que muito pode 
colaborar para uma análise da cultura material do vestir. Outro trecho reflete o descontentamento do autor diante da passividade com que os brasileiros se submetiam à moda estrangeira:

[...] não é preciso acentuar que influência tiveram certas recentes inovações da moda nos costumes brasileiros, dada a nossa propensão, mais talvez do que nenhum outro povo, para aceitar sem exame e imitar sem discussão tudo quanto for novidade, mormente procedendo de Paris, e quão profunda repercussão exercem na nossa mocidade, irradiando, como de rigor, da capital Federal [então, Rio de Janeiro] para os Estados da União (NASCIMENTO, 1976, p.181-212).

O incômodo sentido por Nascimento no tocante à submissão "sem exame" à moda estrangeira vai reverberar em um sentimento nacionalista e numa busca pelo entendimento de uma identidade brasileira ou de uma brasilidade nas publicações posteriores, assuntos recorrentes na bibliografia e nos debates em torno da moda nacional nas últimas três décadas.

Depois da primeira edição de Trs sculos de moda, seguiu-se um período de ostracismo até a publicação da tese de doutorado de Gilda de Mello e Souza sobre a moda no século XIX na Revista do Museu Paulista da Universidade de São Paulo em 1951. ${ }^{20}$ Dali a três outras décadas, em 1986, é publicado Modos de homem \& modas de mulher, de Gilberto Freyre (FREYRE, 1986, p.9), livro em que modos e modas "são considerados sob perspectiva mais sociológica que em puros sentidos literários" e que,

no contexto sócio-histórico brasileiro, os ritmos de relações entre modos e modas vêm, para o autor, variando, tendo sido um, antes de 1850, outro, em épocas seguintes, podendo-se dar destaque à década de 1970, como início de significativo abrasileiramento de modelos importados, por vezes passivamente.

Por esse pensamento de Freire, exposto como "advertência do autor" na apresentação de seu livro, percebemos que pouca mudança de mentalidade foi sentida desde a publicação da primeira edição do estudo de Nascimento com relação à submissão brasileira à moda estrangeira. Esta obra de Freire 
trata de aspectos do nacionalismo que passaram a fazer parte das indagações acerca da moda no Brasil, suas influências e suas inovações. As várias considerações que faz o autor sobre a moda e o Brasil ("nacionalismo e modas", "modas e vários tipos brasileiros de mulher", "o Brasil passivo importador de modas" etc.) revelam uma busca por definir (ou, ao menos, cercar) uma "brasilidade" da moda e analisar suas procedências, suas problemáticas. O estudo de Freire tem de certa forma uma mescla de abordagens antropológicas, históricas, etnográficas, sociológicas, psicológicas. É, sobretudo, um estudo pioneiro no que se propõe a entender: o que constitui modos de viver e vestir brasileiros?

Os interesses sobre a moda recaíram desde Freyre em outras searas e em 1988 é publicado o Moda, luxo e economia, do sociólogo da arte e da cultura José Carlos Durand (São Paulo: Babel Cultural). Já na apresentação ao livro, há uma advertência do autor sobre a abordagem empregada em seu estudo, "passagens sociológicas explícitas" que "podem chocar espíritos propensos a só ver beleza e encantamento no mundo feminino e de sua estética" (1988, p.9). A advertência é lógica. É compreensível que um sociólogo professor de uma instituição reconhecida pela excelência no ensino de administração e economia devesse, naquele momento, justificar seu tema de interesse de pesquisa e colocá-lo à altura da sociologia e distante de questões frívolas como "a beleza do mundo feminino". O sentido dessa advertência, no entanto, se feita hoje seria outro, pois já não é mais possível negligenciar nem a beleza nem o mundo feminino como temas de estudo nas várias áreas das Ciências Humanas.

Nesse trabalho, Durand oferece um panorama histórico da manufatura e indústria da moda, diferenciando sua produção em dois tipos: a alta-costura (de origem francesa, especificamente parisiense) e a costura industrial (de origem anglo-americana que deu origem ao prt-a-porter francês). O autor relata fatos e aspectos relevantes da história da moda no Brasil, e muitas das coisas ali escritas não haviam sido publicadas antes. No capítulo "Moda no Brasil" ele trata superficialmente da chegada das primeiras lojas de moda no Rio de Janeiro no sé- 
culo XIX, das primeiras publicações como a edição brasileira da revista La Saison - A Estação -, do comércio de roupas e tecidos de moda por influência francesa, inglesa e árabe; do desenvolvimento das atividades ligadas à moda como as feiras do setor (FENIT), dos estilistas e jornalistas que passaram a se especializar no assunto. Em "Promoção do Algodão e dos Fios Sintéticos", há menção a contratos de licenciamento de marcas estrangeiras que passaram a ter linhas de produtos confeccionadas no Brasil, caso da Maison Dior, que em 1966 licenciava "meias, perfumes, sapatos e lingeries" (DURAND, 1988, p.77). A ausência de referências às fontes utilizadas, contudo, não permite um desdobramento deste estudo.

A escassez a referências nos estudos sobre as roupas e tecidos explica, em parte, o pouco avanço que se tem feito para conhecer mais e melhor a história do vestir no Brasil. O próprio autor sentiu o peso da ausência de publicações e referências de leitura quando escreveu a sua orientação bibliográfica. Nela indicou uma lista de sete livros estrangeiros de "Histórias da moda que abrangem o século XX", enquanto que, aos títulos em língua portuguesa dedicados a "Histórias da moda no Brasil, abrangendo o século XX", o autor constatou que havia "nada a registrar" (DURAND, 1988, p.134).

\section{Dois João: de Nascimento (1923) a Braga (2004)}

Oitenta e um anos se passaram entre a primeira e a segunda publicação nacional de uma História da Moda. Quase um século separou o estudo de dois pesquisadores homônimos: João Nascimento e João Braga. Há muitas semelhanças entre as trajetórias e as visões desses dois homens. Nascimento fora cronista, desenhista e pintor e dedicou boa parte de sua carreira à escrita de crônicas de costumes, das quais moda parece ter sido um assunto recorrente; a contribuição de seu trabalho pode ser medida por suas conquistas: foi membro fundador da Academia Paraense de Letras e recebeu do governo português a comenda da Ordem de Cristo.

Braga é historiador e também estilista, especialista em 
história do costume, da indumentária e da arte e mestre em história da ciência; e leciona em muitas das escolas de Moda no Brasil, além de trabalhar como consultor de empresas do setor. Ambos escreveram a sua história da moda a partir da visão européia do tempo e espaço, e seus trabalhos são contribuições importantes à bibliografia especializada especialmente para uma audiência formada por alunos dos cursos de graduação. ${ }^{21}$

Braga situa sua obra como baseada "num foco descritivo das identidades vestíveis que foram códigos marcantes de cada época relatada [da pré-história a contemporaneidade]" e que seu texto, "destinado àqueles iniciantes na área que querem conhecer o bê-a-bá da história da moda, [...] permeia a história propriamente dita sem fazer a ideal e atual interdisciplinaridade analítica aprofundada" (BRAGA, 2004, p.15).

De fato, há algumas considerações relevantes e necessárias a ser fazer com relação ao estudo e escrita da (ou de uma) história da moda e do vestir no Brasil: quais são nossas fontes e onde elas estão? Quais são os métodos de trabalho e as abordagens possíveis à moda e à roupa? O que foi estudado e escrito sobre moda no Brasil até hoje? Quem são os autores, os pesquisadores, os historiadores brasileiros e onde eles estão (institucionalmente)?

Novas contribuições começam a responder algumas dessas questões; elas vêm do trabalho de pesquisadores vinculados a museus e arquivos públicos. Dois deles são do Museu Paulista da USP: o historiador Adilson José da Silva (mencionado anteriormente), pesquisador do Departamento de Objetos que tem dois artigos publicados sobre bibliografia especializada disponível em português e teses defendidas com ênfase em temas relacionados a moda; e a conservadora têxtil Teresa Cristina Toledo de Paula, cuja dissertação de mestrado (1998) e tese de doutorado (2004) sobre a conservação e a pesquisa histórica de tecidos no Brasil, apresentam o tema inédito na literatura nacional especializada.

O uso de fontes e as abordagens nos trabalhos citados apontam para alguns caminhos possíveis por onde avançar as pesquisas. As roupas (objetos) são fontes fundamentais des- 


\section{sa história, documentos sobreviventes das ações naturais e artificiais de seleção que ainda aguardam estudos e interpre- tações.}

\section{Notas}

1. Para escrever este texto utilizei particularmente o trabalho de duas autoras inglesas pioneiras na pesquisa historiográfica sobre as roupas: Valerie Cunning (1996) e Lou Taylor (2002, 2004).

2. Este método de pesquisa seria desenvolvido mais tarde por Nora Waugh e Janet Arnold, esta última bastante conhecida por seu estudo de roupas do século XVI da família Médici (TAYLOR, 2004, p.49).

3. Taylor atribui o termo "historiador" aos autores, referindo-se menos à formação acadêmica do que à natureza de seus interesses de pesquisa e trabalho. A autora analisa essa dicotomia do ponto de vista britânico, relacionado às questões de gênero (especialmente feminismo) que ganharam força nas discussões teóricas das ciências humanas a partir da década de 1960. Contudo, os autores por ela citados, apesar de origem inglesa, são internacionalmente os mais influentes.

4. Os trabalhos de Kohler e de Laver são os mais utilizados por historiadores e nas disciplinas de História da Moda nos cursos de bacharelado em Moda no Brasil.

5. As traduções das citações neste artigo são minhas.

6. A coleção de roupas dos Cunnington fora doada e ainda se encontra sob a guarda do Platt Hall (TAYLOR, 2004, p.61).

7. Jennifer Harris é autora de 5,000 years of textiles, um dos mais importantes estudos atuais sobre a história têxtil mundial.

8. Em minha visita ao museu em 1999 (em atividade do programa de mestrado), Jennifer Harris mostrou-se curiosa por conhecer tecidos e trajes brasileiros, visto que o país não estava representado nas coleções têxteis etnográficas da Inglaterra.

9. Enquanto Barthes concentrou sua análise no vestuário de moda, Sahlins contemplou "todos os tipos de vestuário" (ALMEIDA, 1995, p.258).

10. Iniciativa da incansável Káthia Castilho (Universidade Anhembi Morumbi/SP), e de Maria de Fátima Mattos (à época Coordenadora do curso Design de Moda da Instituição Moura Lacerda).

11. Do original: Fashion as communication. London : Routledge, 1996.

12. Do original: Fetish: fashion, sex and power. New York: Oxford University Press, 1996.

13. Do original francês La mode sous / 'occupation. Paris: Editions Payot, 2001.

14. Traduzida do original: ROCHE, Daniel. La culture ds apparences: une histoire du vêtement (XVIIe - XVIIle siècle). Paris : Librairie Arthème Fayard, 1989.

15. É do Centro Universitário SENAC de São Paulo o primeiro mestrado de moda do país, intitulado Moda, Cultura e Arte, iniciado em 2004 e encerrado em 2008 em meio a manifestações de apoio à continuidade do curso por alunos e professores).

16. São eles: Braga (2004); Castilho (2004); Mesquita (2004); Garcia e Miranda (2005); Preciosa (2005); Demestresco (2005); Castilho e Martins (2005); Gibson (2006).

17. Os artigos são: "Vitrinas: entre a tentação e a sedução", de Sylvia Demetresco e Marcelo M. Martins; "Impossível não comunicar", de Cristina Frange; "Moda e comunicação: o jogo da aparência como raiz cultural", de Carol Garcia; "A moda espera dos corpos: um olhar sobre o discurso da 'liberdade de escolha'", de Cristiane Mesquita 
(trata de moda e subjetividade); '" moda e a Comunicação", de Luís Tadeu Dix; "A história dos cursos de design de moda no Brasil", de Dorotéia Baduy Pires, e "Algumas reflexões sobre moda e criação: uma experiência no ensino da moda brasileiro", de Sandra Harabagi.

18. Do original The encyclopaedia of fashion. London: Thames and Hudson, 1986.

19. Agradeço a contribuição da professora Mariza Werneck (PUC/SP) a este respeito.

20. Teresa Cristina Toledo de Paula, conservadora têxtil do Museu Paulista, revelou, em sua tese de doutorado (2004), que o trabalho de Gilda Rocha de Mello e Souza, A moda no sculo XIX: ensaio de sociologia esttica fora inicialmente publicado na Revista do Museu Paulista, trinta e cinco anos antes de ser transformado em livro e publicado sob o título O esprito das roupas: a moda no sculo XIX, pela Companhia das Letras (1986).

21. O livro de Nascimento não está disponível nas bibliotecas das escolas e o único exemplar que pudemos localizar, da edição de 1976, está na Biblioteca Municipal Mario de Andrade, em São Paulo. Sua obra, portanto, é praticamente inacessível à maioria dos alunos dos cursos Moda no país.

\section{Referências}

ABREU, Alice Rangel de Paiva. Avesso da moda: trabalho a domicílio na indústria de confecção. São Paulo: Hucitec, 1986.

ALMEIDA, Adilson José de. A pesquisa acadêmica de moda no Brasil. Fashion Theory: A Revista da Moda, Corpo e Cultura, v. 2, n. 2, p. 127-129, jun. 2003.

ALMEIDA, Adilson José de. Indumentária e moda: seleção bibliográfica em português. Anais do Museu Paulista, São Paulo, v. 3, p. 251-296, jan-dez. 1995.

ALVIM, Zuleika; PEIRÃO, Solange. Mappin 70 anos. São Paulo: Ex Libris, 1985.

ANDRADE, Rita. Bou Soeurs RG7091: a biografia cultural de um vestido. São Paulo, 2008. Tese (Doutorado) - Departamento de História/PUC, 2008.

ANDRADE, Rita. Por debaixo dos panos: cultura e materialidade de nossas roupas e tecidos. In: PAULA, Teresa Cristina Toledo de (Org.). Tecidos no Brasil: museus e coleções. São Paulo: Museu Paulista da USP, 2005, p.72-75. BARNARD, Malcolm. Moda como comunicao. Rio de Janeiro: Rocco, 2003.

BARTHES, Roland. Sistema da moda. Tradução: Lineide do Lago Salvador Mosca. São Paulo: Editora Nacional/EDUSP, 1979.

BENJAMIN, Walter. Rua de mão única. Obras Escolhidas. v. II. São Paulo: Brasiliense, 2000.

BOLLON, Patrice. A moral da mscara. Rio de Janeiro: Rocco, 1993.

BONADIO, Maria Claudia. Moda e sociabilidade: mulheres e consumo na São Paulo dos anos 1920. São Paulo: Senac, 2007. 
BOUCHER, François. 20,000 years of fashion: the history of costume and personnal adornment. New York: Abrams, 1986.

BRAGA, João. Histria da moda: uma narrativa. São Paulo: Editora Anhembi Morumbi, 2004.

CASTILHO, Kathia. Moda e linguagem. São Paulo: Editora Anhembi Morumbi, 2004.

CASTILHO, Kathia; VILLAÇA, Nizia (Org.).O novo luxo. São Paulo: Editora Anhembi Morumbi, 2006.

CASTILHO, Kathia; GALVÃO, Diana. A moda do corpo, o corpo da moda. São Paulo: Editora Esfera, 2002.

CASTILHO, Kathia; MARTINS, Marcelo M. Discursos da moda semitica, design e corpo. São Paulo: Editora Anhembi Morumbi, 2005.

CATELLANI, Regina Maria. Moda ilustrada de A a Z. São Paulo: Manole, 2003.

CIDREIRA, Renata Pitombo. Sentidos da moda: vestuário, comunicação e cultura. Annablume, 2005.

DAMATTA, Roberto. O que faz o brasil, Brasil? Rio de Janeiro: Rocco, 1984.

DEMESTRESCO, Sylvia. Vitrinas em diálogos urbanos. São Paulo: Editora Anhembi Morumbi, 2005.

DICIONÁRIO DA MODA. Guia de referência de termos do mercado têxtil e moda. São Paulo: Instituto Francisca Peixoto, 2002.

dOBRAS. Uma revista de moda mas não só, acadêmica mas nem tanto. São Paulo: Estação das Letras e Cores, 2008.

DUGGAN, Ginger Gregg. O maior espetáculo da Terra. Os desfiles de moda contemporânea e sua relação com a arte performática. Fashion Theory: A Revista da Moda, Corpo e Cultura, edição brasileira, v.1, n.2, p. 3-30, jun. 2002.

DURAND, José Carlos. Moda, luxo e economia. São Paulo: Babel Cultural, 1988.

FREYRE, Gilberto. Modos de homem \& modas de mulher. 3. ed. Record: São Paulo e Rio de Janeiro, 1997 (1.ed. 1986).

FYSKATORIS, Anthoula. O varejo de moda na cidade de São Paulo (19101940): a democratização da moda e a inserção do consumo de baixa renda. São Paulo, 2006. Dissertação (Mestrado) - Programa de História da Pontifícia Universidade Católica de São Paulo, 2006.

GARCIA, Carol; MIRANDA, Ana Paula. Moda comunicao. São Paulo: Editora Anhembi Morumbi, 2005.

GLOSSÁRIO TÊXTIL E DE CONFECÇÃO. Inglês-português. Rio de Janeiro: 
CNI/DAMPI/SENAI/CETIQT, 1986.

GRUMBACH, Didier. Histrias da moda. São Paulo: Cosac Naify, 2009.

GIBSON, William. A construo do imaginrio Cyber. São Paulo: Editora Anhembi Morumbi, 2006.

HARRIS, Jennifer (Ed.). 5,000 years of textiles. London: British Museum Press, 1999. (1. ed. 1993).

LIPOVETSKY, Gilles. Imprio do efmero: a moda e seu destino nas sociedades modernas. Tradução: Maria Lúcia Machado. São Paulo: Companhia das Letras, 1989. 294 p.

LANGLEY, Moore D.The woman in fashion. London: Batsford, 1949.

MALERONKA, Wanda. Fazer roupa virou moda: um figurino de ocupação da mulher (São Paulo 1920-1950). São Paulo: SENAC, 2007.

MENDONÇA, Miriam da Costa Manso Moreira de. O reflexo no espelho: o vestuário e a moda como linguagem artística e simbólica. Goiânia: Editora da UFG, 2006.

MESQUITA, Cristiane. Moda contemporânea: quatro ou cinco conexões possíveis. São Paulo: Editora Anhembi Morumbi, 2004.

MILLER, Lesley Ellis. Cristóbal Balenciaga (1895-1972): the couturiers'couturier. London: V\&A, 2007.

MONNEYRON, Frédéric. A moda e seus desafios: 50 questões fundamentais. São Paulo: Senac, 2008.

NASCIMENTO, João Affonso do. Três séculos de modas. 2. ed. Belém, Pará: Conselho Estadual de Cultura, 1976. 226 p. (Coleção Cultura Paraense, Série Ignácio Moura).

O'HARA, Georgina. Enciclopédia da moda. São Paulo: Companhia das Letras, 1992.

PADILHA, Marcia. A cidade como espetáculo: publicidade e vida urbana na São Paulo dos anos 20. São Paulo: Annablume, 2001.

PALMER, Alexandra. New directions: fashion history studies and research in North America and England. Fashion Theory, Berg, 1997, v. 1, issue 3, p. 297-312, 1997.

PALOMINO, Érika. Babado forte. São Paulo: Publifolha, 1999.

PAULA, Teresa Cristina Toledo de. Inventando moda e costurando histria: pensando a conservação de têxteis no Museu Paulista da USP. São Paulo, 1998. Dissertação (Mestrado) - ECA/USP, 1998.

PAULA, Teresa Cristina Toledo de. Têxteis: avessos, versos e contrários. In: ABREU, Adilson Avansi de (Org.). Quantos anos faz o Brasil? São Paulo: Edusp/IMESP, 2000.

PAULA, Teresa Cristina Toledo de. Tecidos no Brasil: um hiato. 2004. Tese 
(Doutorado) - Escola de Comunicação e Artes, Universidade de São Paulo. PAULA, Teresa Cristina Toledo de (Org.). Tecidos no Brasil: museus e coleções. São Paulo: Museu Paulista da Universidade de São Paulo, 2005.

PRECIOSA, Rosane. Produo esttica: notas sobre roupas, sujeitos e modos de vida. São Paulo: Editora Anhembi Morumbi, 2005 (Coleção Moda e Comunicação / Kathia Castilho, coordenação).

RAINHO, Maria do Carmo Teixeira. A cidade e a moda: novas pretensões, novas distinções - Rio de Janeiro, século XIX. Brasília: Editora Universidade de Brasília, 2002.

REIS, Claudia Barbosa. Indumentria: estudo do acervo do Museu Casa de Rui Barbosa - II. Rio de Janeiro: Fundação Casa de Rui Barbosa, 1999.

ROCHE, Daniel. Cultura das aparncias: uma história da indumentária (séculos XVII-XVIII) São Paulo: SENAC, 2007.

SABINO, Marco. Dicionrio da moda. São Paulo: Campus e Elsevier, 2006.

SANT'ANNA, Denise Bernuzzi de (Org.). Cuidados de si e embelezamento feminino: fragmentos para uma história do corpo no Brasil. In:

Polticas do corpo. São Paulo: Estação Liberdade, 1995a. p.121-140.

SOUZA, Gilda Rocha de Mello e. O esprito das roupas: a moda no século XIX. São Paulo: Companhia das Letras, 1986.

SPENGLER, Airton. Decifrando a moda: glossário. São Paulo: STS, 1993.

STEELE, Valerie. Fetiche: moda, sexo e poder. Rio de Janeiro: Rocco, 1997.

TAYLOR, Lou. The study of dress history. Manchester: Manchester University Press, 2002.

TAYLOR, Lou. Establishing dress history. Manchester: Manchester University Press, 2004.

THOMPSON, E. P. Costumes em comum. São Paulo: Companhia das Letras, 1998.

VEBLEN, Thorstein. The Theory of the leisure class. New York, 1994 (1. ed. 1899).

VEILLON, Dominique. Moda e guerra: um retrato da França ocupada. Rio de Janeiro: Zahar Editor, 2004.

VILLAÇA, Nizia. A edio do corpo: tecnociência, artes e moda. Barueri: Estação das Letras, 2007.

WHITE, Palmer. Poiret. O destino de um grande costureiro. São Paulo: Globo, 1990.

WILSON, Elisabeth. Enfeitada de sonhos. Lisboa: Edições 70, 1989. 
Notas sobre roupa na literatura especializada

\section{Rita Andrade}

Professora do Programa de Pós-graduação em Cultura Visual e do Bacharelado em Design de Moda da Faculdade de Artes Visuais/ UFG. Doutora em História pela PUC/SP e mestre em História dos tecidos e das roupas pela Universidade de Southampton, Inglaterra. Membro do Conselho Editorial da revista Dobras. Tem artigos publicados no Brasil e exterior sobre moda e roupa na perspectiva da cultura material.

E-mail:ritaandrade@hotmail.com 